\title{
A autonomia e a responsabilização dos praticantes no treino em Voleibol. Estudo comparativo de treinadores em função do género
}

\author{
Felismina Pereira \\ Isabel Mesquita \\ Amândio Graça
}

https://doi.org/10.5628/rpcd.09.01.64
Centro de Investigação, Formação,

Inovação e Intervenção em Desporto (CIFI'D)

Faculdade de Desporto

Universidade do Porto

Portugal

\section{RESUMO}

O presente estudo pretendeu analisar a responsabilização e a autonomia conferida aos praticantes pelo treinador na actividade desenvolvida no treino, em Voleibol, em função do género dos treinadores. Participaram neste estudo quinze treinadores, sete do género feminino e oito do género masculino. Os instrumentos utilizados na recolha de dados, entrevista e sistema de observação, foram construídos obedecendo aos requisitos de validação de construção e de conteúdo. $\mathrm{Na}$ análise das respostas dos entrevistados, foi aplicado o método de análise de conteúdo, com recurso ao programa QSR NVivo, versão 7.0, e na análise dos dados relativos ao comportamento pedagógico do treinado em função do género, aplicou-se o teste de MannWhittney e o cálculo do Effect Size. Os resultados apontam em geral para um processo de ensino centrado no treinador, ao que não foi alheio o facto de os praticantes serem pouco responsabilizados na consecução das tarefas, criando situações desfavoráveis na adopção de estratégias instrucionais promotoras da autonomia dos praticantes. Todavia, a abordagem instrucional das treinadoras foi mais responsabilizante, porquanto os sistemas de accountability que adoptaram foram mais precisos e exigentes, o que se repercutiu na concessão de maior autonomia aos praticantes na consecução das tarefas de aprendizagem, suportada pelo recurso mais frequente ao questionamento específico.

Palavras-chave: accountability, responsabilização, autonomia, género dos treinadores, voleibol

\begin{abstract}
The autonomy and responsibility of the players in Volleyball training setting. Comparative study according coaches' gender

The purpose of this study is to examine the accountability and the autonomy conferred by coaches to the players, in volleyball training according to coaches' gender. Fifteen Portuguese coaches, seven female and eight male, participated in this study. The instruments applied, interviews and observation system, were created obeying the requisites of construct and content validation. For the analysis of the coaches' answers, content analysis method was applied, resorting to QSR NVivo version 7.0. For data analysis regarding coaches' pedagogical behaviour according to coaches' gender, Mann-Whittney tests were applied, with calculation of Effect Size. Results indicate a coach-centred teaching approach, supported by little responsibility given to players when executing the training tasks. Subsequently, this approach created situations that did not promote the adoption of instructional strategies aiming at the players' autonomy. Nonetheless, the women coaches' instructional approach was more accountable, inasmuch as their adopted accountability systems were more accurate and demanding, fact that brought on repercussions when conceding more autonomy to the players executing learning tasks, which was also supported by a more frequent use of specific questioning.
\end{abstract}

Key-words: accountability, autonomy, coaches' Gender, volleyball 


\section{INTRODUÇÃO}

Durante largos anos, e até aproximadamente à década de 80 , no ensino em geral e na educação física, em particular, privilegiaram-se abordagens instrucionais centradas no professor, as quais se configuram no recurso prioritário a métodos directivos e formais, baseados num ensino explícito e prescritivo(38). Tal prevalência teve eco no contexto do treino desportivo, sendo que o treinador autoritário foi o mais popular por longo tempo, assente na convicção de que o fundamental era prescrever aos praticantes as tarefas a realizar, não havendo espaço para a problematização dos problemas correntes da prática(31). Liukkonen et al.(29) num estudo aplicado no contexto de treino de jovens, verificaram que os praticantes não participavam na maioria das decisões e, raramente, realizavam actividades que exigissem iniciativa pessoal, para além de serem parcas as actividades desenvolvidas no treino promotoras da autonomia, da responsabilização e da cooperação entre pares. De facto, neste tipo de abordagem, cabe ao treinador a responsabilidade de identificar os problemas do jogo e formular as respectivas soluções (50), podendo resultar daqui praticantes com pobre capacidade decisional, dependentes do treinador nas soluções que adoptam. Contrariamente, nas abordagens instrucionais emergentes na actualidade, filiadas nas ideias construtivistas, o praticante é colocado no centro do processo de ensino/aprendizagem(22), e a ênfase é colocada na necessidade de conceder espaço de problematização ao praticante e de favorecer a emergência de autonomia decisional(50). Nesta perspectiva, o treinador passa a ser visto como um facilitador do processo de aprendizagem, que recorre a estratégias instrucionais, como o questionamento e a responsabilização dos praticantes no cumprimento das tarefas, para fomentar no praticante a emergência do comportamento prospectivo em detrimento do meramente reactivo. Neste particular, oferece especial relevância o recurso ao questionamento para encorajar o praticante a explorar diferentes soluções e a desenvolver a consciência táctica e a compreensão do jogo, possibilitando, paralelamente, o desenvolvimento de um relacionamento afectivo positivo entre o treinador e os praticantes $(9,50)$. Todavia, não importa apenas questionar, mas sobretudo tornar efectiva esta estratégia instrucional, particularmente naquilo que diz respeito às interacções reportadas aos conteúdos substantivos de aprendizagem. Como refere Mesquita(33), estando o questionamento específico directamente relacionado com os conteúdos substantivos de aprendizagem, a sua aplicação pelo treinador permite orientar os praticantes para a percepção calibrada de variáveis especificadoras disponíveis no envolvimento situacional.

Considerando que, na ausência de sistemas de accountability $^{1}$, a prática motora pode resvalar para algo desprovido de significado, onde as tarefas praticadas se desviam substancialmente dos propósitos pedagógicos que as sustentam, a optimização do recurso a estratégias instrucionais promotoras da autonomia decisional passa inequivocamente pela implementação de sistemas de accountability que valorizem a auto-responsabilização dos praticantes pelo seu desempenho nas tarefas aprendizagem. Em conformidade com esta assunção a implementação de sistemas de accountability é crucial, porquanto aumenta o envolvimento e o compromisso dos praticantes, potenciando o cumprimento dos propósitos que norteiam as tarefas de aprendizagem e treino(30), para além de garantir a criação de condições vantajosas para o incremento da autonomia dos praticantes. Mesquita(35) releva a necessidade de os sistemas de accountability serem simultaneamente precisos e exigentes, em relação aos propósitos e conteúdos de aprendizagem, e flexíveis, no sentido de orientarem os praticantes mais por princípios do que por procedimentos, mais pela criatividade do que pelo conformismo.

De facto, a necessidade de responsabilizar os praticantes para melhorar a sua participação ou performance e progressivamente lhes conceder maior espaço de autonomia e compromisso tem vindo a constituir-se uma temática central na agenda da investigação( $(4,14,26,27,30)$. Diferentes estudos $(8,14,24)$ demonstram que, quando os praticantes se sentem responsabilizados pelo cumprimento de determinada tarefa, o compromisso aumenta, o que, consequentemente, promove a ocorrência de condições vantajosas para o atingir de níveis superiores de performance(5).

Contrariamente, a ausência de responsabilização dos praticantes poderá conduzir a um processo de negociação ou mesmo de modificação das tarefas, podendo resultar daí a desvirtuação dos propósitos e con- 
teúdos de ensino e a emergência de práticas que em nada se revêem nos propósitos preconizados pelo treinador $(2,17,20,27)$.

Baseado neste enquadramento conceptual, considera-se pertinente identificar, no âmbito do presente estudo, as abordagens instrucionais prevalecentes no contexto do treino de jovens em Voleibol, no que concerne, especificamente, à responsabilização e autonomia conferida aos praticantes durante a prática. Acresce a este propósito a necessidade de perceber se o género dos treinadores interfere com as decisões instrucionais adoptadas, porquanto a literatura dá conta da prevalência de estilos de intervenção pedagógicos distintos em função do género dos treinadores, mostrando que as treinadoras são mais afectivas(28), para além de recorrerem a estilos menos directivos ${ }^{(47)}$, o que poderá interferir na responsabilização e espaço de autonomia concedido aos praticantes.

As dissimilitudes evidentes em função do género podem encontrar justificação em factores que se revêem nas idiossincrasias próprias à sua construção social, não devendo ser ignoradas na medida em que da sua compreensão e estudo podem resultar práticas mais qualificadas. Ainda mais numa área como o treino desportivo, onde tradicionalmente as mulheres têm menos oportunidade que os homens, tendência que se tem vindo a agravar recentemente. De facto, apesar de no séculos XIX e XX se ter assistido a uma ascensão da posição social da mulher, o que resultou num crescendo de participações e oportunidades desportivas, o número de treinadoras tem vindo a diminuir nos últimos anos ${ }^{(16,19,48)}$. A esta situação não é alheio o facto de padrões sociais e culturais continuarem a ser a grande justificação para a grande discrepância entre o número de treinadores e treinadoras no $\operatorname{activo}^{(1,48)}$, decorrendo esta evidência da persistência de ideias preconceituosas e discriminatórias quanto ao facto de as mulheres serem treinadoras ${ }^{(16)}$. Aliás, como advogam Coakley(10) e Cooper et al.(12), as míticas razões sociais e culturais e os estereótipos sobre a "natural" diferença entre homem e mulher, relativamente ao desporto, servem de fundamentação para se assumir que os homens são melhores treinadores do que as mulheres. Esta assunção traduz-se empiricamente na constatação da preferência das próprias mulheres, enquanto praticantes, por treinadores do género masculino(56). Estes resultados elucidam bem o estatuto de menoridade e subalternidade atribuído ao papel de treinadora desportiva, mesmo se os seus atributos provenientes da construção social associados ao género possam ser uma mais-valia na intervenção do treino desportivo, com particular destaque no contexto infanto-juvenil.

Deste modo, torna-se relevante estudar se as abordagens instrucionais adoptadas pelas treinadoras no treino de jovens em Voleibol se diferenciam claramente dos seus pares masculinos, nomeadamente no respeitante às estratégias instrucionais qualificadoras da intervenção pedagógica, como sejam a responsabilização dos praticantes e a autonomia concedida aos praticantes no decurso das tarefas de aprendizagem.

\section{MATERIAL E MÉTODOS \\ Participantes}

No presente estudo participaram quinze $(n=15)$ treinadores de Voleibol pertencentes à Associação de Voleibol do Porto, Portugal, sendo sete $(n=7)$ do género feminino e oito do género masculino $(n=8)$. No momento da aplicação do estudo, estes treinadores treinavam equipas dos escalões de iniciados $(n=9)$ e juniores $(n=6)$, maioritariamente femininos (80\%). Os participantes do estudo são jovens treinadores em fase inicial de carreira desportiva, apresentando uma média de idades de 26,0 anos para os treinadores e de 26,4 para as treinadoras, e uma média de anos de experiência de treino de 5,5 anos para os treinadores e de 6,4 para as treinadoras. Deste modo, garantiu-se elevada homogeneidade entre os participantes em variáveis que importava não serem discricionárias, como sejam a experiência e a idade dos treinadores e o género dos praticantes. Todos os treinadores concordaram em fazer parte do estudo, tendo sido observado um total de 15 sessões de treino, uma por treinador.

\section{Variáveis e instrumento de observação}

O estudo apresenta como variáveis dependentes o sistema de accountability adoptado pelos treinadores e a autonomia concedida aos praticantes na resolução das tarefas no decorrer da sessão de treino; e como variável independente, o género dos treinadores. 
No sentido de viabilizar o estudo foram aplicados dois instrumentos, um sistema de observação sistemática do comportamento do treinador no treino $\mathrm{e}$ uma entrevista destinado à recolha de informação sobre a representação dos treinadores nas temáticas em estudo.

Na medida em que nenhum dos instrumentos de observação sistemática disponíveis na literatura abrangia na totalidade os problemas e os objectivos do presente estudo, procedeu-se à construção e validação de um instrumento. A construção do instrumento, alicerçou-se em referências teóricas e metodológicas descritas na literatura $(25,38,44)$.

Seguidamente procedeu-se a uma validação de conteúdo, no sentido de averiguar se as dimensões e categorias que o instrumento comporta abrangiam a totalidade dos problemas em estudo, bem como confirmar se as categorias consideradas obedeciam aos pressupostos de exaustividade e exclusividade. Para o efeito, procedeu-se a uma validação por peritagem, com a participação de três peritos, doutorados e especialistas da área da Pedagogia do Desporto, sendo que um deles possui vasta experiência no domínio do treino em Voleibol.

Na Tabela 1, é apresentado o sistema de observação nas suas dimensões de análise e respectivas categorias. Para a análise das representações dos treinadores acerca da responsabilização dos praticantes nas tarefas de aprendizagem e do espaço de problematização concedido no decurso dos treinos, a entrevista aplicada foi de natureza semi-estruturada de resposta aberta. Este tipo de entrevista, o mais utilizado na investigação em ciências sociais(53), permite focar as questões nos objectivos e problemas de pesquisa do estudo através de um guião predefinido, aplicado de modo flexível. Evita-se deste modo a divagação do respondente e a diversão para um grande número de questões, o que tornaria mais difícil a comparação das respostas entre os entrevistados.

Referenciais teóricos disponíveis na literatura da especialidade $(22,25,38,44,50)$ serviram de base para a construção do formulário da entrevista, cuja aplicação ocorreu após a satisfação dos seguintes pressupostos metodológicos: a) o guião de questões previamente elaborado foi submetido a apreciação e aprovado por um painel de especialistas, formado por três professores universitários que lidam habitual- mente com este instrumento de investigação; b) procedeu-se à realização de um estudo piloto com dois treinadores não incluídos na amostra, de forma a averiguar acerca da inteligibilidade, precisão e pertinência das questões da entrevista.

\section{Procedimento de Recolha de Dados}

Foi realizado um contacto anterior com os treinadores, no sentido de confirmar a sua disponibilidade para participar no estudo e para a explicação do objectivo do mesmo, destacando o seu carácter "não avaliativo". O anonimato e a confidencialidade foram garantidos bem como a não utilização indevida ou abusiva das entrevistas e dos treinos observados. Os treinos observados foram estrategicamente seleccionados na parte central do microciclo, ou seja, excluiu-se deliberadamente os treinos que antecediam e sucediam imediatamente à competição do fim-desemana, sendo que todas as equipas se encontravam em igual período competitivo da época desportiva. Com este critério pretendeu-se homogeneizar as características do treino observado(43) em referência à sua localização no microciclo semanal. Do treino observado, foi retirada a parte inicial (aquecimento) e final (relaxamento), tendo sido alvo de análise a parte fundamental do treino, porquanto é nesta parte do treino que são abordados, por excelência, os conteúdos substantivos de aprendizagem ${ }^{(49)}$, sendo relevante no presente estudo especificar os sistemas de accountability adoptados bem como a autonomia concedida aos praticantes em tarefas que remetem para os objectivos prioritários da sessão de treino.

Os treinos foram filmados nos seus ambientes naturais, através de um sistema de câmara de vídeo (Samsung digtal-cam VP-D903iPAL) e de microfone sem fios de longo alcance (Fonestar MSH-135), com receptor conectado à entrada áudio da câmara vídeo e colocado na lapela do treinador para registo das intervenções orais. A câmara de filmar estava colocada, estrategicamente, sobre um tripé na parte do pavilhão que permitia obter o melhor ângulo de filmagem. A anteceder a sessão de treino observada, foi realizada a entrevista, que decorreu num local calmo, escolhido pelo treinador, onde se acautelou a possível interferência de terceiros. As entrevistas foram áudio-gravadas na íntegra e tiveram uma duração que variou entre os trinta e os quarenta minutos. 
Tabela 1. Instrumento de observação relativo ao sistema de accountability e autonomia conferida aos praticantes pelos treinadores em sessões de treino em Voleibol

\section{Sistema de accountability:}

a) Tipo de exigência durante a tarefa:

a.1. Participação/Esforço: o treinador enuncia aspectos volitivos de participação nas tarefas de aprendizagem sem referir informação sobre os conteúdos substantivos de aprendizagem (ex. "Vamos lá, quero que se entreguem à tarefa até ao fim.")

a.2. Desempenho: o treinador refere componentes críticas para a consecução da tarefa, centrando a exigência na qualidade da performance (ex. "Quero que joguem no meio dos apoios e orientados para o alvo.")

a.3. Sem Exigência: o treinador não refere aspectos volitivos nem enuncia componentes críticas para a consecução da tarefa.

b) Reacção do treinador ao in (cumprimento) da tarefa

b.1. Punição: na sequência da tarefa realizada pelo praticante, o treinador determina um castigo, físico ou de outro âmbito (ex. "Como não conseguiram cumprir a tarefa vão fazer 10 flexões de braços."]

b.2. Elogio/ Encorajamento: na sequência da tarefa realizada pelo praticante, o treinador elogia ou encoraja (ex. "Para a próxima vai sair melhor. Basta que te empenhes mais."]

b.3. Indiferente: na sequência da tarefa realizada pelo praticante, o treinador não adopta qualquer comportamento.

c) Indicadores de regulação da tarefa

c.1. Tempo: o treinador estabelece um determinado tempo para o cumprimento da tarefa (ex. "Ao fim de 10 minutos trocam.")

c.2. Critério êxito centrado em indicadores de eficiência: a tarefa é orientada para a qualidade de realização da acção motora (ex. "Quero que contactem a bola acima e à frente da testa com os dedos afastados.")

c.3. Critério êxito centrado em indicadores de eficácia: a tarefa é orientada para o resultado desejável (ex. "Têm que colocar 5 serviços em cada uma das zonas.")

c.4. Critério êxito centrado em indicadores de adaptação: a tarefa é orientada para a realização oportuna e situada da acção motora em função dos constrangimentos situacionais (ex. "No ataque é fundamental que pela leitura do bloco apliquem a técnica que melhor se ajusta.")

\section{Autonomia conferida aos praticantes}

a) Agentes de controlo e regulação da tarefa

a.1. Centrado no treinador: o treinador determina o início, o andamento e o término da tarefa (ex. "Quando eu disser trocam de funções.")

a.2. Centrado no praticante: o treinador determina que serão os praticantes a controlar e a regular o andamento da tarefa (ex. "Dois a dois um de cada lado da rede. Vão contar o número de passagens de rede.)

b) Uso do questionamento

b.1. Questionamento Específico: o treinador coloca questões sobre o conteúdo substantivo de aprendizagem (ex. "Quem está a fazer a cobertura ao bloco?"]

b.2. Questionamento Geral: o treinador coloca questões sobre aspectos organizativos, volitivos ou de compreensão da tarefa sem referir informação sobre os conteúdos substantivos de aprendizagem (ex. “Tens dúvidas sobre o que é para fazer?”)

\section{Procedimentos de Análise dos dados}

Para a análise das decisões instrucionais emergentes nas sessões de treino, recorreu-se à estatística descritiva, destacando as medidas de tendência central e de dispersão, tais como a média e o desvio-padrão, valor mínimo e máximo, frequência e percentagem de ocorrências. Para a comparação de dados aplicou-se o teste da estatística não paramétrica, U de Mann-Whitney, apropriado para amostras de dimensões reduzidas. Adicionalmente calculouse o Effect-size (ES), que indica a magnitude do efeito da acção, sendo que Cohen(11) e Winer et al. (57) referem que valores até 0,2 representam pequena diferença; até 0,5 diferenças moderadas; e superiores a 0,8 , larga diferença. Para efeitos da interpretação e análise dos resultados, assumiu-se o valor de 0,05 para o nível de confiança. 
As entrevistas relativas ao estudo das representações dos treinadores foram transcritas e a cada treinador foi atribuída uma sigla, sendo que, de T1-T7 representam as treinadoras e de T8-T15, os treinadores. Os textos transcritos foram preparados, formatados e introduzidos no programa de análise de dados qualitativos QSR Nvivo, versão 7.0, uma ferramenta adequada para proceder à análise do conteúdo(55). Segundo Bardin(6), a análise de conteúdo possui dois tipos de funções. Uma heurística, na qual existe uma tentativa exploratória de descoberta do material, e uma função de comprovação, através da qual se confirmam ou não as hipóteses formuladas. No âmbito deste estudo, está implícito um certo apriorismo, porquanto várias categorias de análise são extraídas do quadro teórico de referência. Porém, e uma vez que as respostas obtidas nas entrevistas são susceptíveis de fornecer material relevante para o estudo não enquadrável nas categorias definidas a priori, não deixa de estar presente uma função heurística. Este tipo de procedimento, que combina duas formas analíticas, é cada vez mais frequente, dado que, com a combinação dos processos, é possível chegar a um quadro de categorias simultaneamente sensível aos requisitos teóricos e às particularidades do material analisado(3).

Deste modo, dada a inexistência de um quadro conceptual preciso referenciado à temática em estudo, o sistema categorial assentou da conjugação dos referenciais teóricos emergentes na literatura com a análise do conteúdo das respostas dos entrevistados, e que comporta as categorias e respectivas subcategorias constantes na Tabela 2 .

No processo de codificação, foi aplicado o critério lógico-semântico, utilizando-se como unidade de registo a frase com sentido completo classificável numa das categorias da grelha de codificação. A unidade de contexto revela-se essencial para que se possa compreender a significação exacta de uma unidade de registo, utilizando-se o parágrafo que engloba a frase $(6,53)$. No que diz respeito às regras de enumeração, recorremos apenas à regra da presença ou ausência e à regra da frequência. Para a categorização da informação por unidade de registo.

A triangulação dos dados foi realizada no sentido de relacionar os dados emergentes da entrevista com os dados provenientes das decisões instrucionais observadas nas práticas de treino.
Tabela 2. Sistema categorial relativo ao sistema de accountability e abordagens instrucionais prevalecentes no treino em Voleibol

\section{Aplicação de sistemas de accountability [as categorias correspondem às do sistema de observação]}

1.1. Indicadores de regulação da tarefa

1.1.a. Critérios de êxito centrados na eficiência

1.1.b. Critérios de êxito centrados na eficácia

1.2. Exigência durante a prática

1.2.a. Participação/esforço

1.2.b. Desempenho

1.3. Reacção do treinador ao in (cumprimento) da tarefa

1.3.a. Punição

1.2.b. Encorajamento

1.3.c. Indiferente

\section{Abordagens instrucionais prevalecentes}

2.a. Recurso a estratégias instrucionais com prevalência directiva: interacção com os praticantes recorrendo sobretudo à prescrição e onde as decisões relacionadas com o controlo e regulação das tarefas são centradas no treinador.

2.b. Recurso a estratégias instrucionais com prevalência não directiva: utilização predominante do questionamento, como forma de interacção com os praticantes e onde as decisões relacionadas com o controlo e regulação das tarefas são centradas no praticante.

\section{Fiabilidade}

Com o objectivo de testar a objectividade dos nossos resultados, efectuamos a análise intra-observador e inter-observadores para as categorias consideradas, com base no cálculo de percentagem de acordo e desacordos registados, segundo a fórmula de Bellack ${ }^{(54)}$. Foi observada uma sessão de treino de 3 treinadores, perfazendo um parcial de 815 intervenções (18.87\%) e 27 tarefas (22.69\%), ultrapassando consideravelmente os $10 \%$ do mínimo exigível do total da amostra (51). Da análise dos resultados da fiabilidade, constatamos percentagens de acordos que variam entre os 95 e os $100 \%$ (intra-observador e inter-observadores). No sentido de excluir a possibilidade de existirem acordos devidos ao acaso foi aplicado o índice Kappa de Cohen o qual apresentou valores situados entre 0.95 e 1 e entre 0.93 e 1 na fiabilidade intra-observador e inter-observadores, respectivamente. 
No que se refere aos procedimentos relacionados com a fiabilidade de codificação dos dados da entrevista foram utilizados os mesmos procedimentos atrás descritos. Os resultados obtidos na determinação da fiabilidade relativos à classificação de categorias situam-se entre valores que variam de $96 \%$ a $100 \%$ (intra-codificador e inter-codificadores), confirmados pela aplicação do índice Kappa de Cohen, onde os valores se situaram entre 0.97 e 1 e 0.96 e 1 na fiabilidade intra-observador e inter-observador, respectivamente.

\section{APRESENTAÇÃO DOS RESULTADOS}

\section{Análise descritiva}

\section{Sistema de accountability}

$\mathrm{Na}$ Tabela 3 são apresentados os resultados relativos ao sistema de accountability adoptado pelos treinadores no decorrer das sessões de treino.

Tabela 3. Resultados gerais do sistema de accountability utilizado pelos treinadores.

\begin{tabular}{lcc}
\hline \multicolumn{3}{l}{ Indicação do agente de controlo e da regulação da tarefa } \\
\hline \multirow{3}{*}{ Indicação controlo da tarefa } & Frequência & Percentagem \\
Sem indicação controlo tarefa & 43 & $36,1 \%$ \\
Total & 76 & $63,9 \%$ \\
\hline Indicadores de regulação da tarefa & 119 & $100,0 \%$ \\
\hline \multicolumn{3}{l}{} \\
Tempo & Frequência & Percentagem \\
Eficiência & 68 & $57,1 \%$ \\
Eficácia & 24 & $20,2 \%$ \\
Adaptação & 10 & $8,4 \%$ \\
Total & 17 & $14,3 \%$ \\
Tipo de exigência durante a prática & 119 & $100,0 \%$ \\
\hline & & \\
Participação/esforço & Frequência & Percentagem \\
Desempenho & 35 & $29,4 \%$ \\
Sem exigência & 61 & $51,3 \%$ \\
Total & 23 & $19,3 \%$ \\
& 119 & $100,0 \%$
\end{tabular}

Reacção pelo (in)cumprimento da tarefa

\begin{tabular}{lcc}
\hline & Frequência & Percentagem \\
Punição & 15 & $12,6 \%$ \\
Encorajamento & 9 & $7,6 \%$ \\
Indiferente & 95 & $79,8 \%$ \\
Total & 119 & $100,0 \%$ \\
\hline
\end{tabular}

Como se pode constatar, na maior parte das tarefas de aprendizagem $(63,9 \%)$, os treinadores não indicaram o agente de controlo e regulação das tarefas. Todavia é convicção de $86.7 \%$ dos treinadores, patente nas entrevistas, que a aplicação de sistemas de accountability é crucial e que a indicação do agente de controlo e regulação das tarefas é determinante para a estabilização e qualificação do envolvimento e desempenho.

Ainda na Tabela 3, é possível verificar que os indicadores de regulação de tarefas privilegiados pelos treinadores nas sessões de treino assentaram no tempo (57.1\%), seguido dos critérios de êxito orientados para a eficiência (20.2\%). Com menor expressão surgiram os critérios de êxito orientados na adaptação (14.3\%) e, por fim, a eficácia (8.4\%). Numa análise das representações dos treinadores neste domínio, verificouse que a sua grande maioria advoga o uso sistemático de indicadores de regulação da tarefa (73.3\%), onde se denota a enfatização nos critérios de êxito orientados para a eficácia e para a eficiência $(66.7 \%$ e $60 \%$, respectivamente).

Relativamente ao tipo de exigência apontado pelos treinadores para manterem os praticantes empenhados ou para induzi-los a empenharem-se mais nas tarefas, a categoria desempenho surgiu em mais de metade das tarefas de aprendizagem (51.3\%), seguida da participação/esforço (29.4\%) e, por fim, da categoria sem exigência (19.3\%). Estes resultados encontram eco, em grande medida, nas posições perfilhadas pelos treinadores, já que $60 \%$ referem colocar exigências durante a prática para o cumprimento das tarefas de aprendizagem, tanto no que concerne ao desempenho (53.3\%), como à participação/esforço (46.7\%).

Na reacção dos treinadores perante o cumprimento ou não das tarefas, decorrente da observação sistemática, destaca-se claramente a indiferença (79.8\%), sendo que a punição e o elogio/encorajamento apresentam valores substancialmente baixos $(7.6 \%$ e $12.6 \%$ respectivamente). Estes resultados convergem com a posição perfilhada pelos treinadores na entrevista, já que apenas $33.3 \%$ dos treinadores referiram atender ao cumprimento ou não das tarefas de aprendizagem, onde curiosamente é mais salientada a punição (26.7\%) do que o encorajamento $(20.0 \%)$. 
Autonomia conferida aos praticantes

A Tabela 4 apresenta os resultados relativos à autonomia conferida pelo treinador aos praticantes no desenvolvimento das tarefas de aprendizagem.

Tabela 4. Resultados gerais da autonomia concedida aos praticantes.

\begin{tabular}{|c|c|c|}
\hline \multicolumn{3}{|c|}{ Agente de controlo e regulação da tarefa } \\
\hline & Frequência & Percentagem \\
\hline Treinador & 90 & $75,6 \%$ \\
\hline Praticantes & 29 & $24,4 \%$ \\
\hline Total & 119 & $100,0 \%$ \\
\hline \multicolumn{3}{|c|}{ Uso do questionamento durante a prática } \\
\hline & Frequência & Percentagem \\
\hline Geral & 95 & $2,2 \%$ \\
\hline Especifico & 119 & $2,8 \%$ \\
\hline Sem questionamento & 4104 & $99,6 \%$ \\
\hline Total & 4318 & $100,0 \%$ \\
\hline
\end{tabular}

No que concerne à autonomia conferida aos praticantes no controlo e regulação das tarefas, verifica-se que os treinadores assumem maioritariamente esta tarefa, aproximadamente três vezes mais do que os praticantes ( $75.6 \%$ e $24.4 \%$ respectivamente). Pela leitura da Tabela 4, é claramente evidenciado que a ausência de questionamento marca o comportamento dos treinadores durante a realização das tarefas $(99.6 \%)$. Destaca-se ainda que o recurso a questões directamente relacionadas com os conteúdos substantivos de aprendizagem foi aproximado ao do questionamento geral $(2.8 \%$ e $2.2 \%$, respectivamente). Paradoxalmente, a análise das representações dos treinadores deixa perceber que grande parte dos treinadores $(80.0 \%)$ considera que a sua intervenção no treino é realizada com recurso a estratégias menos directivas, especialmente com recurso ao questionamento. Todavia, sublinham a importância de estratégias mais directivas $(73.3 \%)$, principalmente pelo recurso ao feedback prescritivo como estratégia instrucional crucial para orientar os praticantes para os objectivos das tarefas.

\section{Análise comparativa em função do género os treinadores Sistema de accountability}

A Tabela 5 apresenta os resultados das características dos sistemas de accountability aplicados nos treinos em função do género dos treinadores.
Como se pode verificar apenas na reacção do treinador pelo (in)cumprimento das tarefas os treinadores não se distinguiram significativamente em função do género. Relativamente ao agente de controlo e de regulação das tarefas é patente que as treinadoras durante a prática indicaram significativamente mais a quem caberia exercer esta função (Mann-Whitney $\mathrm{U}=$ 6.000; $\mathrm{p}=0.007, E S=.63$ ), enquanto os treinadores omitiram mais essa informação (Mann-Whitney $\mathrm{U}=$ 8.500; $\mathrm{p}=0.022, \mathrm{ES}=.60$ ). Pelos resultados obtidos na entrevista, a utilização de sistemas de accountability durante a prática das tarefas de aprendizagem, com incidência do agente de controlo e de regulação das tarefas, foi sugerida por ambos os grupos, embora com algum ascendente das treinadoras (100\%) em relação aos treinadores (75\%).

No que concerne aos indicadores de regulação da tarefa, constatamos que as treinadoras no decorrer do treino indicaram significativamente mais critérios de êxito orientados para a eficiência (Mann-Whitney $\mathrm{U}=$ 6.000; $\mathrm{p}=0.005, \mathrm{ES}=.51$ ), corroborando em certa medida o entendimento perfilhado na entrevista já que o recurso a critérios de êxito orientados para a eficiência foi mais apontado pelas treinadoras do que pelos treinadores $(57.1 \%$ e $37.5 \%)$, como os excertos de T3 e T4 pretendem ilustrar.

(...) por exemplo, no serviço, quero que lancem a bola alta de forma a cair à frente do pé contrário" (T3, parágrafo 13).

Incido mais no trabalho técnico, especificamente no trabalho de posição base, na posição dos pés, do pé mais avançado, da abertura dos apoios... (T4, parágrafo 17).

Quanto à utilização de tarefas reguladas por critérios de êxito orientados para a eficácia, verificamos uma maior quantidade de referências nos treinadores do que nas treinadoras $(75.0 \%$ e $42.9 \%$, respectivamente), aquando da entrevista, tendência confirmada na observação sistemática do treino, embora sem significado estatístico (Mann-Whitney $\mathrm{U}=16.500$; $\mathrm{p}=0.140$ ). Os excertos do T9 e do T10 evidenciam a operacionalização de alguns critérios de êxito centrados na eficácia.

...nós costumamos fazer muito um exercício aqui no treino em que eles têm 5 possibilidades de side-out e têm que fazer 
Tabela 5. Resultados do sistema de accountability adoptado em função do género dos treinadores.

\begin{tabular}{|c|c|c|c|}
\hline \multicolumn{4}{|c|}{ Indicação do agente de controlo e da regulação da tarefa } \\
\hline & Masculino & Feminino & $\mathrm{p}$ \\
\hline Com indicação & 5,25 & 11,14 & 0,007 \\
\hline Sem indicação & 10,44 & 5,21 & 0,022 \\
\hline \multicolumn{4}{|c|}{ Indicadores de regulação da tarefa } \\
\hline & Masculino & Feminino & $\mathrm{p}$ \\
\hline Tempo & 8,94 & 6,93 & 0,380 \\
\hline CE Eficiência & 5,25 & 11,14 & 0,005 \\
\hline CE Eficácia & 9,44 & 6,36 & 0,114 \\
\hline CE Adaptação & 8,44 & 7,50 & 0,669 \\
\hline \multicolumn{4}{|c|}{ Tipo de exigência durante a prática } \\
\hline & Masculino & Feminino & $\mathrm{p}$ \\
\hline Participação/esforço & 10,44 & 5,21 & 0,022 \\
\hline Desempenho & 6,12 & 10,14 & 0,078 \\
\hline Sem exigência & ?,81 & 8,21 & 0,856 \\
\hline \multicolumn{4}{|c|}{ Reacção pelo (in)cumprimento da tarefa } \\
\hline & Masculino & Feminino & $p$ \\
\hline Punição & 7,88 & 8,14 & 0,901 \\
\hline Encorajamento & 8,88 & 7,00 & 0,171 \\
\hline Indiferente & 8,62 & 7,29 & 0,555 \\
\hline
\end{tabular}

3 pontos de $1^{a}$ bola" (T9, parágrafo 15$)$.

...têm que fazer auto passe e ataque para o bloco individual, em que só muda de atleta quando fizerem 5 blocos, é esse o critério de êxito (T10, parágrafo 21 ).

Pela observação sistemática, verifica-se ainda que o tipo de exigência centrado na participação/esforço é mais utilizado pelos treinadores (Mann-Whitney $\mathrm{U}=$ 8.500; $\mathrm{p}=0.022$, $E S=.58$ ), o que vai ao encontro das representações evidenciadas por este grupo na entrevista, já que advogam o recurso à participação/esforço em mais larga escala (62.5\%) do que as treinadoras (28.6\%). O seguinte excerto do T11 comprova este entendimento.

...sempre que possível tento dar muitos feedbacks, muito reforço positivo, para que se sintam motivados. Às vezes acho que até é demais... (T11, parágrafo 19).

Por sua vez, as treinadoras mostraram recorrer mais no treino a exigências centradas no desempenho, sendo esta diferença próxima do significado estatístico (Mann-Whitney $U=13.00 ; \mathrm{p}=0.078$ ). A importância do recurso ao desempenho, enquanto exigência prioritária a realçar nas tarefas, é relevada por ambos os grupos nas entrevistas $(50.0 \%$ para os treinadores e $42.9 \%$ para as treinadoras). O excerto que se segue do T12 evidencia este aspecto.

Vou tentar responsabilizar as atletas. Por exemplo se $01^{\circ}$ toque não sai a colega não pode atacar. A atleta só sai da zona de ataque se pontuar ou se ela própria errar e não pelo erro da colega. Se errar logo na recepção ela não vai rodar...por isso vou responsabilizar a recebedora para que a atacante possa atacar (T12, parágrafo 20).

Relativamente à reacção pelo cumprimento ou não da tarefa apesar de não se verificar diferenças significativas no decorrer do treino em função do género, e embora esta decisão instrucional não seja destacada 
Tabela 6. Resultados da autonomia concedida aos praticantes em função do género dos treinadores

\begin{tabular}{lccc}
\hline Agentes de controlo e regulação da tarefa & & & \\
\hline & Masculino & Feminino & $\mathrm{p}$ \\
Treinador & 9,81 & 5,93 & 0,091 \\
Praticantes & 5,75 & 10,57 & 0,028 \\
\hline Uso do questionamento durante a prática & & & $\mathrm{p}$ \\
\hline & Masculino & Feminino & 0,275 \\
Geral & 6,54 & 9,21 & 0,047 \\
Especifico & 6,50 & 9,71 & 0
\end{tabular}

na entrevista, os treinadores advogam recorrer mais à punição que as treinadoras $(37.5 \%$ e $14,3 \%$, respectivamente). Os excertos da T4 e da T1 denotam a relevância do castigo físico como meio de punição.

Se não conseguirem elas vão ter uma punição para que se preocupem com aquilo, que se preocupem que tem que sair direitinho porque senão não saem dali (T4, parágrafo 17). Se for um de recepção por cada falha têm um castigo físico, se for um exercício de pontuação, quando falham ou retiro ponto ou têm um castigo físico (T1, parágrafo 23 ).

O recurso ao elogio/encorajamento também é evidenciado pelos treinadores na entrevista, com alguma supremacia $(25.0 \%)$ em relação às treinadoras (14.3\%), embora não seja destacado em larga escala por nenhum dos grupos. Um excerto do T14 invoca o recurso ao elogio/encorajamento perante praticantes com pouca autonomia.

Este é um grupo que depende muito do feedback, têm muito pouca autonomia e por isso depende do feedback constante, da correcção constante, parece que estão à espera do feedback, seja positivo ou negativo (T14, parágrafo 20).

\section{Autonomia conferida aos praticantes}

A Tabela 6 apresenta os resultados relativos à autonomia conferida aos praticantes na prática das tarefas de aprendizagem em função do género dos treinadores.

Considerando os agentes de controlo e da regulação da tarefa, verifica-se que, quando o treinador é o agente de controlo e de regulação da tarefa, os grupos não se distinguem (Mann-Whitney $\mathrm{U}=13.500$; $\mathrm{p}=0.091$ ). Todavia, quando o agente de controlo e de regulação da tarefa é o praticante, verifica-se que as treinadoras concedem mais aos praticantes a responsabilidade de desempenhar esta função (MannWhitney $\mathrm{U}=10.500 ; \mathrm{p}=0.0028, \mathrm{ES}=.50$ ). No que concerne ao recurso do questionamento geral, esta estratégia instrucional não se diferenciou em função do género dos treinadores (Mann-Whitney $U=19.500 ; p=0.275)$. Pela análise das representações, é claro em ambos os géneros o recurso a estratégias instrucionais mais e menos directivas $(85.7 \%$ e $67.9 \%$, respectivamente), consoante o momento didáctico a que se referenciam. Daí emerge a ideia da importância da prescrição nos momentos iniciais antes da realização da tarefa e do questionamento para fornecer pistas que conduzam os praticantes para a interpretação dos cenários situacionais. Os excertos da T7 e do T13 são elucidativos nesta matéria.

Acho que tanto a prescrição como o questionamento são importantes, porque há alturas e há atletas que precisam mais de umas do que outras. Inicialmente uso mais a prescrição, mas se começar a perceber que já não é por falta de saberem o que se está a passar mas antes por esquecimento ou por habituação ao erro, passo para o questionamento (T7, parágrafo 22).

Normalmente pergunto para ter a ideia se elas sabem porque erraram, porque elas já estão na fase de pensar (T13, parágrafo 18). 
Todavia, verifica-se uma certa prevalência, no discurso das treinadoras, da valorização de estratégias mais directivas, comparativamente aos seus pares masculinos ( $85.7 \%$ e $62.5 \%$ respectivamente), fundamentalmente através do recurso à informação prescritiva. Interessante é o facto de reconhecerem o recurso em excesso à prescrição em detrimento do questionamento, salientando a necessidade de alterar este comportamento (exemplo do excerto da T1).

Ultimamente tenho optado mais pelo questionamento... tenho tentado mudar, porque eu sei que é um erro meu, mas continuo com muita tendência para reagir, corrigir, mais do que questionar, acho mesmo que é um erro meu, tenho noção disso (T1, parágrafo 25).

A utilização do questionamento específico revelou-se diferenciadora em função do género dos treinadores, sendo que as treinadoras recorreram mais a este tipo de estratégia do que os treinadores (Mann-Whitney $\mathrm{U}=16.000 ; \mathrm{p}=0.047, \mathrm{ES}=.95)$. Esta estratégia promotora da autonomia funcional dos praticantes é valorizada de sobremaneira por ambos os grupos, na entrevista, com alguma supremacia dos treinadores $(87.5 \%)$ relativamente às treinadoras $(71.4 \%)$. Os excertos do T15 e do T21 são ilustrativos das preocupações dos treinadores neste domínio.

Eu tento sempre antes de cada exercício falar com eles, corrigi-los antecipadamente, o que eles têm de fazer, mas sintome sempre obrigado, durante o exercício a perguntar se ele acha que está assim, como é que tem que estar (T15, parágrafo 21).

Eu utilizo muito o questionamento. Pergunto-lhe o porquê para que elas também percebam e não façam as coisas porque o treinador mandou, mas porque sabem que aquilo realmente faz sentido. Utilizo muito o questionamento (T2, parágrafo 17).

\section{DISCUSSÃO}

\section{Sistema de accountability adoptado}

\section{pelos treinadores em geral}

Apesar de os treinadores, de uma forma geral, considerarem importante responsabilizarem os praticantes pelo controlo da actividade e pela regulação da qualidade da prática, o sistema de accountability adoptado revelou fragilidades em diferentes domínios.
O facto de os treinadores não referirem, na maioria das vezes, o agente de controlo e regulação das tarefas de treino oferece condições para que as tarefas praticadas se possam desviar substancialmente do prescrito.

Do mesmo modo, apesar de os treinadores valorizarem o recurso a indicadores qualitativos da performance centrados na eficiência e na eficácia, evidencia-se a prevalência no treino de indicadores de regulação da tarefa centrados no tempo, o que mostra alguma precariedade no sistema de controlo e regulação da actividade dos praticantes. De facto, este indicador apenas controla a quantidade da actividade motora dos praticantes, não significando que a qualidade de prática seja suficiente para que se verifique melhoria na performance e que esteja assegurado o alinhamento entre a tarefa praticada e os objectivos prescritos ${ }^{(32,46)}$. A necessidade de controlar a qualidade da actividade motora dos praticantes, particularmente nas tarefas que remetem para a prática dos conteúdos substantivos de aprendizagem, é realçada pela investigação(21, 46). Particularmente nos jogos desportivos, onde a coexistência de múltiplas soluções para os problemas correntes confere à qualidade de prática importância acrescida ${ }^{(40)}$, o recurso a indicadores de regulação das tarefas centrados nas diferentes dimensões do desempenho (eficiência, eficácia e adaptação) é determinante na orientação dos praticantes para a consecução dos objectivos delineados para as tarefas de aprendizagem ${ }^{(45)}$. O Voleibol, por exigir a sustentação da bola no espaço aéreo como prerrogativa de sucesso, evidencia que tomar o tempo de prática como indicador de regulação e controlo da tarefa é deveras insuficiente, sendo determinante o recurso a aspectos qualitativos da performance, no sentido de garantir a qualidade de prática nas tarefas de aprendizagem(34).

Relativamente ao tipo de exigência colocado aos praticantes na prática de tarefas de aprendizagem, é de realçar o facto de os treinadores frequentemente incidirem no desempenho em detrimento da participação/esforço, corroborando a importância salientada nas entrevistas da explicitação destes critérios, para que sejam efectivos o desenvolvimento na tarefa e a prossecução dos objectivos. A focalização da exigência no desempenho exige elevado conhecimento substantivo sobre os conteúdos de ensino, como foi 
confirmado por Hastie e Vlaisavljevic(25), ao compararem professores com domínios diferenciados de expertise na matéria de ensino. Por seu turno, Pereira et al.(41), num estudo com jovens treinadores de Voleibol com reduzida experiência de treino, verificaram a prevalência de exigências centradas na participação/esforço relativamente ao desempenho.

Um outro aspecto a realçar é o facto de a generalidade dos treinadores do presente estudo não adoptar qualquer medida de contingência em resposta ao envolvimento ou desempenho dos praticantes nas tarefas de aprendizagem. Tinning e Siedentop ${ }^{(52)}$ reforçam a necessidade de os sistemas de accountability comportarem aplicações de consequência, porquanto constituem elementos reguladores e estabilizadores da actividade dos praticantes. Destaca-se ainda, no presente estudo, que na presença de reacção de consequência pelo cumprimento ou não das tarefas, a punição foi mais utilizada do que o elogio (encorajamento), aspecto corroborado pelos treinadores na entrevista. Tal remete para um estilo de intervenção que atribui ao o erro um sentido pejorativo e se admite o recurso à actividade física como meio de punição, em claro contraste com o evidenciado em estudos recentes com treinadores experts de Futebol, quer em equipas de jovens(15), quer em equipas seniores $(42,43)$, onde o elogio/encorajamento apresentou valores francamente superiores aos da punição. O uso do exercício físico como forma de punição pelo incumprimento das tarefas em última análise associa o exercício físico a algo que pretende ser sentido como desagradável (punição) em vez de o valorizar como conteúdo e meio de aprendizagem, que permite o desenvolvimento dos praticantes(39).

\section{Autonomia conferida aos praticantes pelos treinadores em geral}

No presente estudo, evidencia-se que, de uma forma geral, os treinadores não conferiram autonomia aos praticantes na consecução das tarefas, sendo evidente esta constatação em diferentes aspectos.

Nomeadamente, no que se refere ao agente de controlo $e$ de regulação da tarefa, esta função foi maioritariamente desempenhada pelos treinadores, o que sugere que os treinadores em estudo afastam-se claramente do recurso a abordagens instrucionais que colocam os praticantes no centro dos processos de aprendizagem e que incentivam atitudes pró-activas e deliberadas, no sentido de os responsabilizar pela própria aprendizagem $(18,23,36)$.

No presente estudo, embora os treinadores apontem para a necessidade de recorrer ao questionamento, porquanto promove liberdade processual na interpretação das situações de aprendizagem e na compreensão do erro(13), o uso que deles fizeram no treino foi deveras reduzido, e quando existiu não se remeteu aos conteúdos substantivos de aprendizagem. Diferentes estudos aplicados no contexto do treino desportivo, tanto ao nível do desporto juvenil $(15,37)$, como em equipas seniores de nível profissional (7, 42, 43) evidenciam um recurso precário ao questionamento no decorrer das sessões de treino, denotando a prevalência de estilos directivos no contexto do treino.

\section{Abordagens instrucionais prevalecentes em função do género dos treinadores}

No presente estudo, o género dos treinadores revelou-se diferenciador, não só nos sistemas de accountability adoptados, como na autonomia concedida aos praticantes no decorrer da prática.

Ao nível do sistema de accountability, apenas na categoria reacção de consequência pelo in (cumprimento) das tarefas os treinadores não se distinguiram das treinadoras, sendo relevante o facto de, nas restantes categorias, as treinadoras adoptarem sistemas de accountability mais precisos e exigentes do que os treinadores. Tal é evidente na indicação do agente de controlo e da regulação da tarefa; na prescrição de indicadores orientados para a eficiência; e na exigência de desempenho em detrimento da participação/esforço, corroborando em traços gerais a valorização conferida pelas treinadoras nas entrevistas ao recurso a estratégias instrucionais promotoras da responsabilização do praticante no cumprimento das tarefas. Estes resultados sugerem uma maior preocupação por parte das treinadoras em especificar mais a informação e serem mais exigentes ao nível do desempenho, em oposição aos treinadores, que reforçam mais os aspectos volitivos, ao colocarem a ênfase na participação/esforço, e ao especificarem menos os indicadores de controlo e de regulação da tarefa. Diferentes estudos $(5,8,14,24)$ realçam que, quando são sujeitos a sistemas de accountability, os praticantes 
tendem a agir de acordo com os critérios estabelecidos, o que reforça a importância da sua qualidade em referência aos propósitos das tarefas de aprendizagem.

As diferenças encontradas nos sistemas de accountability implementados justificaram, em grande medi$\mathrm{da}$, distintas decisões instrucionais ao nível da autonomia concedida aos praticantes. $\mathrm{O}$ facto de as treinadoras atribuírem maior responsabilização aos praticantes no controlo e regulação das tarefas pode, em parte, dever-se ao recurso a sistemas de accountability mais precisos e exigentes. A indicação do controlo e da regulação das tarefas por parte das treinadoras, a enfatização de indicadores de eficiência e a colocação de exigências centradas no desempenho garantem, logo à partida, um maior comprometimento dos praticantes com os objectivos a perseguir, criando-se condições para que eles próprios possam controlar e regular a prática, ou seja, serem os principais agentes reguladores e estabilizadores da aprendizagem. Outro aspecto digno de destaque prende-se com o recurso mais frequente, por parte das treinadoras, ao questionamento específico. De novo, estamos em crer que o maior controlo dos procedimentos de realização da tarefa, veiculados por indicadores de eficiência, e a incidência no desempenho permitiram às treinadoras recorrer mais ao questionamento específico, isto é, centrado nos conteúdos de aprendizagem, porquanto os praticantes já possuíam informação substantiva prévia que lhes permitia orientaremse para a prossecução de objectivos específicos em referência aos conteúdos de aprendizagem. Estes resultados evidenciam, ainda, que as treinadoras recorreram mais vezes a estratégias menos directivas do que os treinadores, o que vai ao encontro do verificado no estudo realizado por Rosener(47). Todavia, há que realçar que esta estratégia instrucional foi pouco utilizada por ambos os grupos, apesar de expressarem, mais enfaticamente as treinadoras, a necessidade de a utilizar mais no processo de ensino-aprendizagem em referência aos conteúdos substantivos de aprendizagem. A este propósito, vários autores $(18,37)$ destacam a importância do uso do questionamento, quando se foca em aspectos centrais dos conteúdos de aprendizagem, nomeadamente ao nível da apreciação e compreensão dos cenários de prática; como por exemplo, no caso particular dos jogos desportivos, o questionamento focado sobre aspectos decisionais. A vantagem pedagógica de tal questionamento deriva do facto de ser a partir da informação implícita, veiculada nas questões, que os praticantes canalizam a atenção para a percepção calibrada de variáveis especificadoras disponíveis nos envolvimentos de aprendizagem ${ }^{(9,33)}$.

\section{CONCLUSÕES}

Os resultados do presente estudo apontam para um processo de ensino centrado no treinador, ao que não foi alheio o facto de os praticantes serem pouco responsabilizados na consecução das tarefas o que, consequentemente, criou situações desfavoráveis para a adopção de estratégias instrucionais promotoras da autonomia dos praticantes.

Os treinadores, de uma forma geral, adoptaram como exigência prioritária nas tarefas propostas, a qualidade de desempenho, embora esta seja fundamentalmente regulada pelo tempo de realização e sem indicação do agente de controlo e regulação. Para além disso, não assumem frequentemente qualquer comportamento de consequência pelo cumprimento ou não das tarefas de aprendizagem por parte dos praticantes. Relativamente à autonomia concedida aos praticantes durante a prática, esta foi praticamente inexistente, porquanto competiu ao treinador grande parte do papel de controlo e regulação das tarefas. A este nível, releva-se o parco recurso ao questionamento pelos treinadores, quando este se afigura na actualidade como estratégia instrucional crucial, na promoção da autonomia dos praticantes no decorrer da prática.

Tendo presente que os participantes deste estudo eram jovens treinadores com pouca experiência profissional, o facto de ter sido nota dominante a adopção de estilos de intervenção directivos pode deverse, em grande medida, aos conteúdos curriculares e estratégias de ensino e aprendizagem valorizadas na sua formação inicial, enquanto treinadores. Se tomarmos por referência os resultados provenientes da investigação empírica realizada em contextos reais de prática no desporto juvenil, revelar-se-á particularmente importante actualizar modelos e estratégias de formação de treinadores que possam concorrer para a qualificação das práticas de treino. Saliente-se, todavia, que a abordagem instrucional 
das treinadoras foi mais responsabilizante, na medida em que estas recorreram com maior frequência a sistemas de accountability orientados para a qualidade do desempenho; apontaram mais critérios reguladores do desempenho, centrados na eficiência; e indicaram mais o agente de controlo e regulação da tarefa. A adopção de sistemas de accountability mais precisos e exigentes pelas treinadoras repercutiu-se na adopção de um estilo de intervenção mais centrado no praticante, patente na maior autonomia concedida ao nível do controlo e de regulação tarefas de aprendizagem e no recurso mais frequente ao questionamento específico.

A diferenciação de estilos de intervenção pedagógicos em função do género exige, contudo, confirmação em futuros estudos, porquanto o número de participantes envolvidos no presente estudo é deveras reduzido, no sentido de legitimar a sua generalização.

\section{AGRADECIMENTOS}

Trabalho financiado pela Fundação para a Ciência e Tecnologia (FCT) de Portugal com a referência SFRH/BD//45386/2008.

\section{NOTA}

1 termo sem correspondência directa precisa em português, que remete para as ideias de responsabilização e prestar contas

\section{CORRESPONDÊNCIA}

\section{Isabel Mesquita}

Faculdade de Desporto

Rua Dr. Plácido Costa, 91

4200-450 Porto

Portugal

E-mail: imesquita@fade.up.pt

\section{REFERÊNCIAS}

1. Acosta RV, Carpenter LJ (2000). Women in intercollegiate sport: a longitudinal study Twenty Three year updates 1977-2000. Women in Sport \& Physical Activity Journal 9:141144.

2. Alexander KR (1982). Behavior Analysis of Tasks and Accountability in Physical Education. Graduate School, vol $\mathrm{PhD}$. The Ohio State University Ohio.

3. Araújo L (1995). Designing and refining hierarchical coding frames. In: Kelle U (ed) Computer-aided qualitative analysis: Theory, methods and practice. Sage London, pp 96104.

4. Balderson DW (2001). The effects of a personal accountability and personal responsibility model on urban elementary student positive social and off task behaviors. Educational Leadership College of Education, vol PhD. University of Nevada Las Vegas.

5. Balderson DW, Sharpe T (2005). The effects of personal accountability and personal responsibility instruction on select off-task and positive social behaviors. Journal of Teaching in Physical Education 24:66-87.

6. Bardin L (1977). Análise de conteúdo. Lisboa: Edições 70.

7. Bloom G, Crumpton R, Anderson J (1999). A systematic observation study of the teaching behaviors of an expert basketball coach. Sport Psychologist 13:157-170.

8. Brobst B, Ward P (2002). Effects of public posting, goal setting, and oral feedback on the skills of feamale soccer players. Journal of Applied Behavior Analysis 35:247-257.

9. Chambers KL, Vickers JN (2006). Effects of bandwidth feedback and questioning on the performance of competitive swimmers. Sport Psychologist 20:184-197.

10. Coakley JJ (2001). Sport in society: issues and controversies. McGraw-Hill Dubuque,IA.

11. Cohen J (1988). Statistical power analysis for the behavioral sciences. L. Erlbaum Associates Hillsdale, N.J.

12. Cooper M, Hunt K, Camille POB (2007). Women in coaching: Exploring female athletes' interest in the profession. Chronicle of Kinesiology \& Physical Education in Higher Education 18:8-19.

13. Cross D (2000) How to coach the mastery of the mental game. The Coach, FIVB 1:6-8.

14. Crouch D, Ward P, Patrick C (1997). The effects of peermediated accountability on task accomplishment during Volleyball drills in elementary physical education. Journal of Teaching in Physical Education 17:26-39.

15. Cushion CJ, Jones RL (2001). A systematic observation of professional top-level youth soccer coaches. Journal of Sport Behavior 24:354-376.

16. Demers G (2007). To Coach or Not? Soccer Journal 52:2430.

17. Doyle W (1983). Academic work. Review of Educational Research 53:159-199.

18. Dyson B, Griffin LL, Hastie P (2004). Sport Education,Tactical Games, and Cooperative Learning: Theoretical and Pedagogical Considerations. Quest (Human Kinetics) 56:226-240.

19. Everhart CB, Chelladurai P (1998). Gender differences in preferences for coaching as an occupation: The role of selfefficacy, valence, and perceived barriers. Research Quarterly for Exercise and Sport 69:188-200.

20. Graça A (1997). O Conhecimento Pedagógico do Conteúdo no Ensino do Basquetebol. Dissertação de Doutoramento. 
Faculdade de Ciências do Desporto e de Educação Física, Universidade do Porto.

21. Graham K (1987). A description of academic work and student performance during a middle school volleyball unit. Journal of Teaching in Physical Education 7:22-37.

22. Gréhaigne J-F, Godbout P (1995). Tactical knowledge in team sports from a constructivist and cognitivist perspective. Quest 47:490-505.

23. Hastie P, Curtner-Smith M (2006). Influence of a hybrid Sport Education - Teaching Games for Understanding unit on one teacher and his students. Physical Education and Sport Pedagogy 11:1-27.

24. Hastie P, Saunders S (1992). A study of task systems and accountability in an elite junior sports setting. Journal of Teaching in Physical Education 11:376-388.

25. Hastie P, Vlaisavljevic N (1999). The relationship between subject-matter expertise and accountability in instructional tasks. Journal of Teaching in Physical Education 19:22-33.

26. Hebert EP, Landin D, Solmon MA (2000). The impact of task progressions on students' practice quality and taskrelated thoughts. Journal of Teaching in Physical Education 19:338-354.

27. Jones D (1992). Analysis of task systems in elementary physical education classes. Journal of Teaching in Physical Education 11:411-425.

28. Lacy AC, Goldston PD (1990). Behavior analysis of male and female coaches in high school girls' basketball. Journal of Sport Behavior 13:29-39.

29. Luikkonen J, Laasko L, Telama R (1996). Educational perspectives of youth sport coaches: Analysis of observed coaching behaviors. International Journal of Sport Psychology 27:439-453.

30. Lund J (1992). Assessment and accountability in secondary physical education. Quest 44:352-360.

31. Martens R (1999). Os grandes treinadores são grandes comunicadores e motivadores. In: Adelino J, Vieira J, Coelho O (eds) Seminário Internacional Treino de Jovens. Centro de Estudos e Formação Desportiva, Secretaria de Estado do Desporto, Lisboa, pp 5-15.

32. Mesquita I (1993). Estudo descritivo e comparativo das respostas motoras de jovens voleibolistas de diferentes níveis de desempenho nas situações de treino e competição. Espaço 1(2):59-76.

33. Mesquita I (2005). A contextualização do treino no Voleibol: a contribuição do construtivismo. In: Araújo D (ed) O contexto da decisãa. A aç̧ão táctica no desporto. Visão e contextos, Lisboa, pp 355-378.

34. Mesquita I (2006). Ensinar bem para aprender melhor o jogo de voleibol. In: Tani G, Bento JO, Peterson R (eds) Pedagogia do Desporto. Editora Guanabara Koogan, Rio de Janeiro, pp 327-344.

35. Mesquita I (2008). A magnitude adaptativa da técnica nos jogos desportivos. Fundamentos para o treino. In: Tavares F, Graça A, Garganta J, Mesquita I (eds) Olhares e contextos da performance nos jogos desportivos. Faculdade de Desporto, Universidade do Porto, pp 93-107.

36. Mesquita I, Graça A (2002). A perspectiva construtivista da aprendizagem no ensino dos jogos desportivos. Cultura e contemporaneidade na educação física e desporto. E agora? Coleção Prata da Casa (edição especial), pp 133-139.

37. Mesquita I, Sobrinho A, Rosado A, Pereira F, Milistetd M (2008). A systematic observation of youth amateur volley- ball coaches behaviours. International Journal of Applied Sport Sciences 20:37-58.

38. Metzler MW (2000). Instructional models for physical education. Allyn and Bacon. Boston.

39. Pagnano K, Langley DJ (2001). Teacher perspectives on the role of exercise as a management tool in physical education. Journal of Teaching in Physical Education 21:57-74.

40. Parker M, O'Sullivan M (1983). Modifying ALT-PE for game play contexts and other reflections. In mSR (ed) Journal-of-teaching-in-physical-education

41. Pereira F, Carneiro D, Mesquita I (2008). Instructional analyse of youth volleyball coach on task presentation. Actas del II Congresso Internacional de Ciencias del Deporte. Universidade de Vigo Pontevedra, Espanha.

42. Potrac P, Jones R, Armour K (2002). 'It's all about getting respect': The coaching behaviors of an expert English soccer coach. Sport, Education \& Society 7:183.

43. Potrac P, Jones R, Cushion C (2007). Understanding power and the coach's role in professional English soccer: A preliminary investigation of coach behavior. Soccer \& Society 8:33-49.

44. Rink J (1993). Teaching physical education for learning. Mosby St. Louis.

45. Rink JE (1994). Task presentation in pedagogy. Quest (Champaign; Ill.) 46:270-279.

46. Rink JE, Werner P (1987). Student responses as a measure of teacher effectiveness. In: Barrette GT (ed) Myths, models, and methods in sport pedagogy: Proceedings of the Adelphi AIESEP '85 World Sport Conference (1985: Adelphi University). Human Kinetics Publishers Champaign, Ill, pp 199-206.

47. Rosener JB (1990). Ways women lead. Harvard Business Review 68:119-125.

48. Rostkowska E (2007). Women and sport: a historical outline and contemporary social and physiological issues. Studies in Physical Culture \& Tourism 14:169-175.

49. Siedentop D, Tannehill D (2000). Developing teaching skills in physical education. Mayfield Pub. Co. Mountain View, Calif.

50. Souza A, Oslin J (2008). A player-centered approach to coaching. JOPERD: The Journal of Physical Education, Recreation \& Dance 79:24-30.

51. Tabachnick BG (1989). Using multivariate statistics. Harper \& Row New York; London.

52. Tinning R, Siedentop D (1985). The characteristics of tasks and accountability in student teaching. Journal of Teaching in Physical Education 4:286-299.

53. Vala J. (2007). Análise de conteúdo. In: Santos Silva A, Madureira Pinto J (eds), Metodologia das Ciências Sociais. Edições Afrontamento (14 ${ }^{\mathrm{a}}$ Edução), Porto, pp.101-128.

54. Van der Mars H (1989). Observer Reliability: Issues and Procedures. In: Darst PW, Zakrasjek DB, Mancini V (eds) Analyzing Physical Education and Sport Instruction. Human Kinetics Books Champaign, Illinois, pp 53-80.

55. Weitzman E (2000). Software and qualitative research. In: Lincoln NDY (ed) Handbook of qualitative research. Sage Publications Thousand Oaks, CA; London, pp 803-820.

56. Williams JM, Parkhouse BL (1988). Social Learning Theory as a Foundation for Examining Sex Bias in Evaluation of Coaches. Journal of Sport \& Exercise Psychology 10:322-333.

57. Winer BJ, Brown DR, Michels KM (1991). Statistical principles in experimental design. New York: McGraw-Hill. 